\title{
FORUM
}

\section{Psychotropic prescribing in HIV}

E Reid, C Orrell, K Stoloff, J Joska

Division of Neuropsychiatry, Department of Psychiatry and Mental Health, Faculty of Health Sciences, University of Cape Town E Reid, MB ChB, FC Psych (SA)

K Stoloff, MB ChB, FC Psych (SA)

J Joska, MB ChB, MMed (Psych), PhD, FC Psych (SA)

Desmond Tutu HIV Centre, Institute of Infectious Diseases and Molecular Medicine and Department of Medicine, Faculty of Health Sciences, University of Cape Town

C Orrell, $\mathrm{MB} \mathrm{ChB}$

Corresponding author: J Joska (john.joska@uct.ac.za)

Disclaimer. Drug profiles, adverse effects and drug-drug interactions have been shortened to include the most common or serious, and are not intended to be exhaustive.

Psychiatric disorders frequently co-occur with HIV, as preceding conditions or consequent to HIV infection. This potentially compromises HIV diagnosis and antiretroviral (ARV) treatment adherence. We provide a brief guide to the diagnosis and treatment of common mental disorders in people living with HIV/AIDS, including: prescribing psychotropics in HIV; neuropsychiatric side-effects of ARVs and other medications commonly prescribed in HIV; and the diagnosis and treatment of depression, anxiety, psychosis, agitation, sleep disturbance, pain, and mania. Psychotropic treatments recommended were drawn primarily from those available in the public sector of South Africa.

S Afr J HIV Med 2012;13(4):194-188. DOI:10.7196/SAJHIVMED.863

Psychiatric disorders frequently cooccur with HIV infection, as conditions preceding or consequent to infection. A high degree of adherence to highly active antiretroviral therapy (HAART) is required to prevent the development of resistant viral strains and to minimise the risk of medication failure. Psychiatric co-morbidities potentially compromise adherence to antiretroviral therapy (ART) and can complicate HIV diagnosis and treatment. Although close collaboration between physicians, psychiatrists and other members of the multidisciplinary team is the ideal, psychiatric support is not readily available in certain settings. This article is intended to guide the diagnosis and psychotropic treatment of common mental disorders in people living with HIV/AIDS (PLWHA).

Many psychotropics are taken for $\geq 6$ months, and both psychotropics and antiretrovirals (ARVs) are metabolised by the cytochrome P450 enzyme system, necessitating consideration of pharmacokinetic interactions. There also needs to be awareness of the differences in medication responses and tolerability in this population. Here we summarise: prescribing psychotropics in HIV; neuropsychiatric side-effects of ARVs and other medications commonly prescribed in HIV; and the diagnosis and treatment of depression, anxiety, psychosis, agitation, sleep disturbance, pain, and mania. The psychotropic treatments recommended here were drawn primarily from those available in the public sector of South Africa (SA).

\section{Psychotropics in HIV: basic principles}

A few simple points should be kept in mind when considering the management of mental disorders in HIV-infected individuals. Firstly, patients with HIV infection are generally very sensitive to medication side-effects as they often metabolise drugs more slowly, have less lean body mass and have compromised blood-brain barrier functioning. Although most patients ultimately tolerate standard doses of most medications, it is advisable to start at low doses and escalate dosing slowly over time., ${ }^{1,2}$ Furthermore, PLWHA often receive multiple medications (ARVs, antibiotics, tuberculosis (TB) medications, etc.). Consequently, healthcare providers need to avoid prescribing complex regimens (e.g. daily dose instead of twice daily, where possible), anticipate drug interactions, and consider possible mood, behavioural and cognitive effects of medications such as ARVs.

The fact that treating HIV infection and related conditions is essential for optimal psychiatric care is often underappreciated. Close collaboration between psychiatrists, physicians, nursing staff and all members of the multi-disciplinary healthcare team is crucial. It is important to make the distinction between primary and secondary psychiatric symptoms (e.g. 
those caused by other medications, delirium, central nervous system (CNS) infections, etc.), as results of standard psychiatric treatment may be inadequate if these are not addressed. ${ }^{1}$

\section{ARV neuropsychiatric side-effects}

The introduction of HAART has transformed HIV infection from a death sentence to a chronic treatable illness. Unfortunately, most ARVs have neuropsychiatric side-effects (Table 1), ${ }^{2}$ most commonly insomnia and headache, with efavirenz (EFV) being the agent most often implicated. These symptoms usually emerge shortly (within 3 months) after commencing ARVs and abate on withdrawal thereof. Although EFV is not absolutely contra-indicated in patients with a history of severe mental illness, patients should be informed of potential side-effects and closely monitored for any emergence or exacerbation of symptoms. Furthermore, where possible, alternative ARVs should be considered. The optimal HAART regimen for patients with
CNS disease remains to be established. It is unclear whether ARV regimens with better CNS penetration are superior to others, ${ }^{3}$ but there is consensus that optimal peripheral viral suppression is necessary. ${ }^{4}$

\section{Depression}

Depressive disorder is common in HIVpositive individuals, with a prevalence of $11.1 \%$ for major depressive disorder and $29.9 \%$ for mild depression in SA clinics. ${ }^{5}$ It has been suggested that depression is often under-diagnosed ${ }^{2}$ and insufficiently managed. ${ }^{6}$ The following screening questions may prove helpful in identifying patients requiring further treatment or referral:

- 'During the past month, have you often been bothered by feeling down, depressed or hopeless?'

- 'During the past month, have you often been bothered by little interest or pleasure in doing things?'

- 'Is this something with which you would like help?'
It is also important to ask patients about suicidal thoughts, self-esteem, feelings of guilt or worthlessness, and outlook. Although the Diagnostic and Statistical Manual of Mental Disorders (Fourth Edition) (DSM-IV) includes problems with sleep, energy and appetite as diagnostic criteria for depression, these may be HIV-related.

If the patient answers 'yes' to one or more of the above questions, it is helpful to differentiate between mild-moderate and severe depression, to inform further management. In mild-moderate depression, patients usually experience transient or mild symptoms occasionally, have low levels of distress, and do not have suicidal thoughts or plans. Such symptoms can often be in relation to a recent diagnosis or the commencement of ARV treatment. These patients can be referred to a supportive adherence counsellor or can be considered for referral for psychotherapy where psychologists are available. In cases of severe depression, patients often have persistent, severe symptoms, high levels of distress and

\section{Table 1. ARV side-effects}

\begin{tabular}{|c|c|c|}
\hline Class & Agent & Side-effects ${ }^{*}$ \\
\hline \multirow{5}{*}{$\begin{array}{l}\text { Nucleoside reverse } \\
\text { transcriptase inhibitors } \\
\text { (NRTIs) }\end{array}$} & Didanosine (ddI) & - Common: insomnia, mania \\
\hline & Lamivudine (3TC) & - Rare: insomnia, mania, restlessness, agitation, delirium, depression, irritability \\
\hline & Stavudine $(\mathrm{d} 4 \mathrm{~T})$ & $\begin{array}{l}\text { - Headache, insomnia, mania, abnormal dreams, anxiety, depression, } \\
\text { somnolence, emotional lability }\end{array}$ \\
\hline & Tenofovir (TDF) & $\begin{array}{l}\text { - Common: aesthenia, depression, insomnia, anorexia (possibly related to } \\
\text { co-use of EFV) }\end{array}$ \\
\hline & Zidovudine (AZT) & $\begin{array}{l}\text { - Common: insomnia, anorexia, dizziness } \\
\text { - Rare: confusion, mania, convulsions, anxiety, somnolence }\end{array}$ \\
\hline $\begin{array}{l}\text { Non-nucleoside reverse } \\
\text { transcriptase inhibitors } \\
\text { (NNRTIs) }\end{array}$ & Efavirenz (EFV) & $\begin{array}{l}\text { - Common: depression, dizziness, insomnia, somnolence, impaired } \\
\text { concentration, vivid dreams, and anxiety } \\
\text { - Rare: agitation, paranoia, delusions, euphoria, confusion, amnesia, } \\
\text { depersonalisation, hallucinations, suicidal ideation, convulsions, false-positive } \\
\text { cannabinoid test }\end{array}$ \\
\hline \multirow[t]{3}{*}{ Protease inhibitors (PIs) } & Lopinavir/ritonavir (LPV/r) & - Rare: parasthaesia, insomnia, reduced libido, anxiety, abnormal dreams \\
\hline & Ritonavir (RTV) & - Common: aesthenia, circumoral and peripheral paresthaesia, altered taste \\
\hline & Atazanavir (ATV/r) & $\begin{array}{l}\text { - Common: dizziness, insomnia } \\
\text { - Rare: depression, confusion, amnesia, abnormal dreams, anxiety }\end{array}$ \\
\hline \multirow[t]{2}{*}{ Antibacterials } & Co-trimoxazole & - Rare: insomnia, depression, anorexia, apathy \\
\hline & Isoniazid (INH) & $\begin{array}{l}\text { - Common: peripheral neuropathy } \\
\text { - Rare: agitation, depression, hallucinations, paranoia, impaired memory }\end{array}$ \\
\hline \multirow[t]{3}{*}{ Other } & Metronidazole & - Rare: CNS toxicity, agitation, depression, delirium, seizures \\
\hline & Amphotericin B & $\begin{array}{l}\text { - Common: headache } \\
\text { - Rare: delirium, agitation, anorexia, lethargy, diplopia }\end{array}$ \\
\hline & Steroids & - Euphoria, mania, depression, psychosis, confusion \\
\hline
\end{tabular}


Table 2. Side-effects, drug interactions and advantages of concurrent SSRI use with ART

\begin{tabular}{|c|c|c|c|c|}
\hline Agent & Dose & Side-effects & Drug interactions $^{8,9}$ & Notes \\
\hline Fluoxetine & $\begin{array}{l}20-60 \\
\mathrm{mg} / \text { day }\end{array}$ & $\begin{array}{l}\text { Nausea, dyspepsia, } \\
\text { abdominal pain, anxiety } \\
\text { (especially in first } 10 \\
\text { days), headache, tremor, } \\
\text { sexual dysfunction, } \\
\text { hyponatraemia, } \\
\text { insomnia and agitation }\end{array}$ & $\begin{array}{l}\text { LPV/r: may increase fluoxetine } \\
\text { levels - increased risk of serotonin } \\
\text { syndrome }\end{array}$ & $\begin{array}{l}\text { - Advantages: low cost, available at } \\
\text { most centres } \\
\text { - Agitation can be a big problem } \\
\text { in the first few days: adequate } \\
\text { explanation and reassurance can } \\
\text { reduce impact } \\
\text { - Safe in overdose }\end{array}$ \\
\hline Citalopram & $\begin{array}{l}20-60 \\
\mathrm{mg} / \text { day }\end{array}$ & As for fluoxetine & $\begin{array}{l}\text { - Not a potent inhibitor of most } \\
\text { cytochrome-P450 enzymes: few drug } \\
\text { interactions } \\
\text { - Use with caution with NSAIDs/ } \\
\text { warfarin }\end{array}$ & $\begin{array}{l}\text { - Advantage over fluoxetine: starting } \\
\text { dose can be halved (10 mg), and } \\
\text { fewer drug interactions } \\
\text { - Safe in overdose }\end{array}$ \\
\hline
\end{tabular}

\section{Table 3. Side-effects, drugs interactions and advantages of concurrent TCA use with ART}

\begin{tabular}{|c|c|c|c|c|}
\hline Agent & Dose & Side-effects & Drug interactions ${ }^{8,9}$ & Notes \\
\hline Amitriptyline & $\begin{array}{l}25-150 \\
\text { mg/day } \\
\text { (usually } \\
\text { taken at } \\
\text { night) }\end{array}$ & $\begin{array}{l}\text { Dry mouth, blurred vision, } \\
\text { constipation, urinary retention, } \\
\text { sedation, arrhythmia } \\
\text { - Contra-indicated if myocardial } \\
\text { infarct in preceding } 6 \\
\text { months, cardiac conduction } \\
\text { abnormalities or prostatism }\end{array}$ & $\begin{array}{l}\text { RTV: increases levels } \\
\text { and thereby the } \\
\text { antimuscarinic effects } \\
\text { of amitriptyline (reduce } \\
\text { the dose) }\end{array}$ & $\begin{array}{l}\text { - Lethal in overdose: not suitable for } \\
\text { patients at risk of suicide } \\
\text { - Dry mouth can be a problem with oral } \\
\text { candida } \\
\text { - Usual dose of } 25 \mathrm{mg} \text { for insomnia } \\
\text { or pain is often not sufficient as an } \\
\text { antidepressant - may need }>3 \text { tablets } \\
\text { - Useful if sedation/analgesia is required }\end{array}$ \\
\hline Imipramine & $\begin{array}{l}75-150 \\
\mathrm{mg} / \text { day }\end{array}$ & $\begin{array}{l}\text { As for amitriptyline, but less } \\
\text { sedating }\end{array}$ & & \\
\hline
\end{tabular}

suicidality. These patients should be referred to psychiatric services and/or treatment with antidepressant medication should be initiated.

\section{Antidepressants}

Using more than one antidepressant should be avoided, as the risk of serotonin syndrome may be increased in HIV-positive patients. ${ }^{2}$ The syndrome, which constitues a medical emergency, presents with pyrexia, sweating, diarrhoea, hyperreflexia, myoclonus, loss of consciousness and seizures.

In general, the duration of treatment with antidepressant medication depends on whether or not the patient has experienced previous depressive episodes. For a first episode, medication should generally be continued for 6 - 12 months to prevent relapse. Treatment should be continued for 2 - 3 years in the event of a patient's second or third episode, and lifelong medication should be considered for $>3$ prior episodes.

St John's wort, a herbal product with antidepressant effects, may reduce the plasma concentrations and clinical effects of EFV, nevirapine (NVP) and lopinavir/ritonavir $(\mathrm{LPV} / \mathrm{r})$. Patients must therefore be informed that its concurrent use with these ARVs is contra-indicated.

First-line agents include the serotonin selective re-uptake inhibitors (SSRIs), fluoxetine (for patients on first-line ART regimens) or citalopram (for patients on second-line regimens or receiving protease inhibitors (PIs)). In most public sector facilities, treatment with citalopram needs to be initiated by a psychiatrist. The side-effects, drug interactions and potential advantages of these SSRIs are outlined in Table 2.

If the patient has a co-morbid sleep disorder or chronic pain, tricyclic antidepressants (TCAs), such as amitriptyline or imipramine, should be considered (Table 3). These can be prescribed as monotherapy: 100 - $150 \mathrm{mg} /$ day, or $25-50 \mathrm{mg} /$ day as augmentation.

In patients with co-morbid anxiety and/or patients who have not responded to SSRIs, the use of venlafaxine (Efexor) - a serotonin and noradrenaline re-uptake inhibitor (SNRI) could be considered. The drug is not available at all centres and needs to be initiated by a psychiatrist (at a dose of $37.5 \mathrm{mg} /$ day, increased to a maximum of $225 \mathrm{mg} /$ day). Treatment with venlafaxine should never be stopped abruptly, as discontinuation symptoms can occur. Potential side-effects include nausea, insomnia, dry mouth, somnolence, sweating, headache, nervousness, constipation, sexual dysfunction and elevation of blood pressure at higher doses. The drug should be avoided in patients at risk of arrhythmia.

\section{Anxiety}

Anxiety is a normal human emotion and may be adaptive in many circumstances. However, when it is present for prolonged periods of time, is excessive in relation to the person's current life stressors, or interferes with daily functioning, an anxiety disorder may be present. Anxiety symptoms often mimic common mental conditions and may occur as part of depression, or alone. It is important to exclude and treat physical causes that can resemble the physical symptoms of anxiety, such as thyroid disease, cardiac disease and seizures. The DSM-IV 
Table 4. Benzodiazepine use with ART

\begin{tabular}{|c|c|}
\hline \multicolumn{2}{|c|}{ Benzodiazepines (short-term prescribing on } \\
\hline Long-acting (half-life $>20$ hours) & $\begin{array}{l}\text { - Diazepam (Pax, Valium): } 2 \text { - } 30 \mathrm{mg} \text { (oral or IV; never IM) up to } 3 \text { times daily } \\
\text { - Clonazepam (Rivotril): } 0.5 \text { - } 2 \mathrm{mg} \text { twice daily }\end{array}$ \\
\hline Intermediate-acting (12 - 24 hours) & $\begin{array}{l}\text { - Lorazepam (Ativan, Tranqipam): } 1 \text { - } 12 \mathrm{mg} \text { (oral, IM or sublingual) up to } 3 \\
\text { times daily } \\
\text { - Alprazolam (Alzam, Xanor): } 0.25 \text { - } 4 \mathrm{mg} \text { (see interactions below) twice daily }\end{array}$ \\
\hline Short-acting (6 - 12 hours) & - Oxazepam 10 - $30 \mathrm{mg}$ twice daily \\
\hline Ultra-short-acting ( $<6$ hours) & $\begin{array}{l}\text { - Midazolam (Dormicum): } 7.5 \text { - } 15 \mathrm{mg} \text { (see interactions below) usually stat dose, } \\
\text { but may be used up to } 3 \text { times daily }\end{array}$ \\
\hline \multicolumn{2}{|l|}{ Benzodiazepine interactions with $\mathrm{ARVs} \mathrm{s}^{\mathrm{s}, 9}$} \\
\hline Diazepam & $\begin{array}{l}\text { - Use with caution with EFV and LPV/r: may need dose adjustment because of } \\
\text { increased sedation, confusion and respiratory depression }\end{array}$ \\
\hline Clonazepam & $\begin{array}{l}\text { - EFV: possible increase or decrease in clonazepam levels; avoid combination } \\
\text { - NVP: possible decrease in clonazepam concentrations and symptoms of } \\
\text { withdrawal } \\
\text { - RTV: likely to increase levels of clonazepam - use with caution }\end{array}$ \\
\hline Alprazolam & $\begin{array}{l}\text { - EFV: may increase levels of alprazolam - avoid } \\
\text { - RTV: increases alprazolam effect when RTV is started; after } 10 \text { days no } \\
\text { significant interaction } \\
\text { - NVP: may reduce alprazolam effect }\end{array}$ \\
\hline Midazolam & $\begin{array}{l}\text { - Do not co-administer with EFV, indinavir or } \mathrm{LPV} / \mathrm{r} \\
\text { - Use with caution with NVP }\end{array}$ \\
\hline Lorazepam/oxazepam & - No clinically significant interaction expected \\
\hline
\end{tabular}

Table 5. Approach to prescribing psychotropics for the agitated patient

\begin{tabular}{|c|c|c|c|}
\hline Step & Agent & Dose & Notes \\
\hline \multirow{2}{*}{$\begin{array}{l}\text { Oral (first step } \\
\text { after non- } \\
\text { pharmacological } \\
\text { treatment) }\end{array}$} & Lorazepam & 1 - 2 mg (maximum 12 mg/day) & Repeat after $45 \mathrm{~min}$ to a maximum of $12 \mathrm{mg} /$ day \\
\hline & Promethazine & $20-25 \mathrm{mg}$ & Daily \\
\hline \multirow{3}{*}{$\begin{array}{l}\text { IM/IV (second step } \\
\text { after oral measures } \\
\text { have failed/are not } \\
\text { possible) }\end{array}$} & Lorazepam & $1-4 \mathrm{mg} \mathrm{IM}$ & $\begin{array}{l}\text { Have flumazenil to hand in case of respiratory } \\
\text { depression }\end{array}$ \\
\hline & Haloperidol & $5 \mathrm{mg} \mathrm{IM}$ & $\begin{array}{l}\text { Should be the last drug considered as incidence of } \\
\text { acute dystonia is high }\end{array}$ \\
\hline & Diazepam & $10 \mathrm{mg}$ over $10 \mathrm{~min}$ IV (never IM) & $\begin{array}{l}\text { Repeat after } 10 \text { min if insufficient effect (up to } 3 \\
\text { times) }\end{array}$ \\
\hline
\end{tabular}

distinguishes between the following anxiety disorders:

- generalised anxiety disorder (GAD): excessive and pervasive worry and tension about a variety of events and activities in daily life, associated with somatic symptoms

- panic disorder: recurrent, unexpected sudden attacks of overwhelming anxiety

- phobias: excessive fears of specific objects (e.g. spiders) or situations (e.g. flying or social situations)
- post-traumatic stress disorder (PTSD): distressing dreams or flashbacks, nervousness, poor sleep and avoiding reminders following a life-threatening or traumatic event

- obsessive-compulsive disorder (OCD): repetitive, uncontrollable thoughts or images that are disturbing; or an inability to cease performing rituals or repetitive actions.

If symptoms of the above disorders are present for $\geq 1$ month, where possible, we advise considering pharmacotherapy and referral to a psychologist. SSRIs are considered first-line treatment. Importantly, people with anxiety disorders may be particularly prone to adverse effects and tolerate high initial doses poorly. ${ }^{10}$ Patients with anxiety generally require higher doses of SSRIs than those with depression; however, medication should be titrated up cautiously to moderate side-effects. Antidepressants for anxiety may need to be taken for 12 months after the remission of symptoms, depending on the diagnosis. 
Either fluoxetine (for patients on first-line ART regimens) or citalopram (for patients on second-line regimens or receiving PIs) could be commenced at half the usual starting dose. Citalopram needs to be psychiatrist-initiated, but has the advantage over fluoxetine of being a scored tablet, making it easier to start at half the usual dose $(10 \mathrm{mg})$. Venlafaxine (psychiatrist-initiated) should be considered for patients who have not responded to SSRIs.

Benzodiazepines (Table 4) provide rapid symptomatic relief of anxiety, but because of their potential to cause physical dependence and withdrawal symptoms, ${ }^{11}$ and the potential for abuse, these drugs should be used at the lowest effective dose for the shortest period of time ( $<3$ weeks). Benzodiazepines should be used in conjunction with SSRIs during treatment initiation. Caution should be exercised because of serious interactions with ARVs, particularly ritonavir (RTV), and especially with alprazolam, midazolam and triazolam. Lorazepam and oxazepam have the least number of interactions with ARVs. Benzodiazepines also cause or exacerbate cognitive impairment and are sedating; therefore, patients must be advised not to drive, operate machinery or drink alcohol concurrently with their use.

\section{Psychosis}

Psychosis can occur at any time during the course of HIV disease. A psychotic syndrome includes at least 2 of the following symptoms:

- delusions (fixed false beliefs)

- hallucinations (auditory and other)

- disorganised speech or thought

- disorganised behaviour.

Psychotic disorders include schizophrenia, substance-induced psychosis, and psychosis secondary to a general medical condition such as HIV. Reported rates of new-onset psychosis in HIV-positive patients range from $0.5 \%$ to $15 \% .{ }^{12}$

It is essential to differentiate psychotic symptoms caused by delirium or encephalopathy, to identify and treat the underlying cause; although short-term symptomatic treatment may include low-dose antipsychotics. In delirium, the psychotic symptoms may occur in the context of fluctuating attention, sleep/wake disturbance and poor orientation.

\section{Anti-psychotics}

Importantly, with regard to prescribing antipsychotics, HIV-positive patients may be more susceptible to extra-pyramidal side-effects (EPSEs), neuroleptic malignant syndrome and tardive dyskinesia.
Antipsychotics should always be initiated at the lowest effective dose and for the shortest period of time necessary. Atypical or secondgeneration antipsychotics (SGAs), where available, are generally preferred over firstgeneration antipsychotics, because of the decreased risk of EPSEs. Risperidone is the most widely studied atypical antipsychotic (or SGA), and generally appears to be safe, although levels have been reported to increase with concurrent RTV use., ${ }^{213}$ An overlap in metabolic side-effect profiles, e.g. weight gain, dyslipidaemia and impaired glucose tolerance of the SGAs and ARVs (PIs and nucleoside reverse transcriptase inhibitors (NRTIs) in particular), complicates the risk-to-benefit equation. ${ }^{14,15}$

Beside the interactions between risperidone and RTV, antipsychotics do not generally significantly inhibit or induce P-450 enzymes and can safely be added to HAART regimens without causing toxicity or HAART failure. Theoretically, RTV may increase the serum levels of haloperidol; therefore, close monitoring of adverse effects is advised.

The use of clozapine in HIV-positive patients is not routinely recommended, although it may be helpful in otherwise medically stable patients with higher CD4 cell counts. ${ }^{2}$ It is not

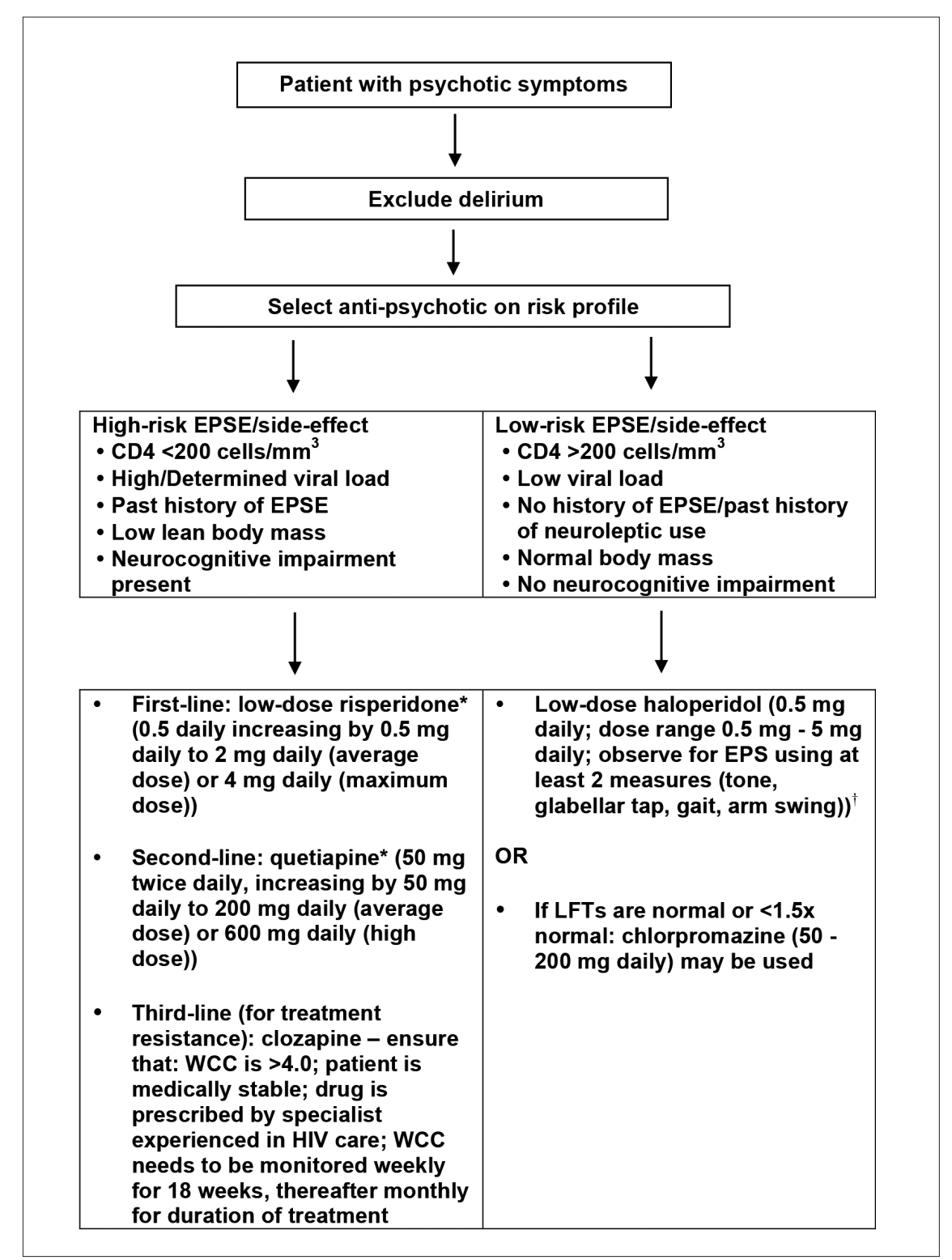

Fig. 1. Decision tree for initiating appropriate anti-psychotic treatment for psychosis in HIV-infected individuals. EPSE = extra-pyramidal side-effects; $W C C=$ white cell count; $L F T s=$ liver function tests. *Risperidone and quetiapine may be initiated ONLY by a psychiatrist.

${ }^{\dagger}$ Depot medications are not contra-indicated. Consider a zuclopenthixol depot if clinically indicated; use a test dose of $50-100 \mathrm{mg}$, and repeat in 1 week. Thereafter, the depot can be administered monthly. 
known whether HIV-positive patients receiving clozapine have a greater risk of agranulocytosis; therefore, extremely close monitoring of white cell count is recommended. Clozapine should only be initiated by a psychiatrist. The drug should be used with caution with LPV and $\mathrm{RTV}^{8,9}$ as this could increase clozapine plasma concentrations, resulting in an increased risk of arrhythmias, seizures and haematological effects.

A guide to initiating appropriate treatment is provided in Fig. 1. Benzodiazepines can be added in the initial stages for agitation or aggressive or disruptive behaviour. Following diagnosis, a depot preparation can be given if adherence is likely to be a problem (or if the patient chooses it). A test dose should be considered.

\section{Agitation}

Aggressive or disruptive behaviour can occur in the context of psychiatric illness, physical illness, substance abuse or personality disorder. This can put staff and patients at risk. In general, it is important to attempt to examine the patient as thoroughly as possible before sedation to establish the underlying aggravating factors. It is also crucial to gain help from nursing staff, doctors and security staff where possible. The safety of the clinician, other patients and staff must be ensured. Non-pharmacological methods should be attempted first, e.g. talking down, distracting, and reassuring the patient. The patient must not be threatened, as this often escalates the situation. Oral treatment must be offered first and biperiden must be available if neuroleptics are introduced. Drug interactions between benzodiazepines and ARVs, and the approach to prescribing psychotropics in the agitated patient are summarised in Tables 4 and 5 , respectively.

\section{Sleep disturbance}

A patient with insomnia may have difficulty with falling asleep, early-morning wakening and/or frequent waking during the night. Before treating insomnia with drugs (Table 6), it is important to consider and address underlying reversible causes such as depression, mania, pain, medication side-effects, substance abuse, and poor sleep hygiene. It must be ascertained whether the patient has realistic expectations of sleep and whether other medications are being given at appropriate times, e.g. stimulating drugs in the morning and sedating drugs at night. If medication is prescribed, then the lowest effective dose for short-term use only must be used, and patients must be advised of interactions with alcohol.

\section{Pain}

Pain symptoms are common in HIV infection and may be caused by painful neuropathy, headaches, cancers and secondary infections. Pain disorders may be acute or chronic, with the latter often accompanied by depression, anxiety, and/or sleep disorders. In addition to analgesia use, psychotropics are frequently used to ameliorate pain symptoms:

- TCAs (e.g. amitriptyline at doses 25 $75 \mathrm{mg}$ at night): refer to the section on 'Depression' for further information. Other antidepressants should be considered if co-morbid depression is present. Duloxetine is an antidepressant registered for chronic pain but is not on State code in SA.

- Anti-convulsants: carbamazepine is not advised because of interactions with ARVs. ${ }^{8,9}$ Gabapentin (Lyrica) is used in chronic pain, but is not freely available.

\section{Bipolar affective disorder/mania}

The essential characteristic of a bipolar mood disorder is one or more manic (or hypomanic) episodes with/without depressive episodes. Mania is a recognised presentation in HIVinfected individuals. A manic episode, which is severe enough to impair functioning or warrant hospitalisation, is characterised by abnormal and persistently elevated, expansive or irritable mood, with: grandiosity; decreased need for sleep; talkativeness; flight of ideas/ accelerated thoughts; distractibility; and/or increased involvement in pleasurable activities with potentially negative consequences, e.g. excessive buying or sexual indiscretions.

\section{Mood stabilisation}

Management is described in Fig. 2. HIV-positive individuals may be more sensitive to the side-

\section{Table 6. Available classes of psychotropics for insomnia*}

\begin{tabular}{lll}
\hline Agent & Dose & Side-effects \\
\hline Promethazine & $10-25 \mathrm{mg}$ & $\begin{array}{l}\text { Can cause dry mouth and 'hangover' } \\
\text { effect }\end{array}$ \\
Amitriptyline & $10-25 \mathrm{mg}$ & $\begin{array}{l}\text { Useful in patients with peripheral } \\
\text { neuropathy }\end{array}$ \\
Oxazepam & $15-30 \mathrm{mg}$ & $\begin{array}{l}\text { Risk of dependency; prescribe no } \\
\text { more than 14 days' supply, unless } \\
\text { prescribed by a psychiatrist or } \\
\text { neurologist }\end{array}$ \\
& \\
& \\
${ }^{*}$ Refer to the text for ARV drug interactions. &
\end{tabular}

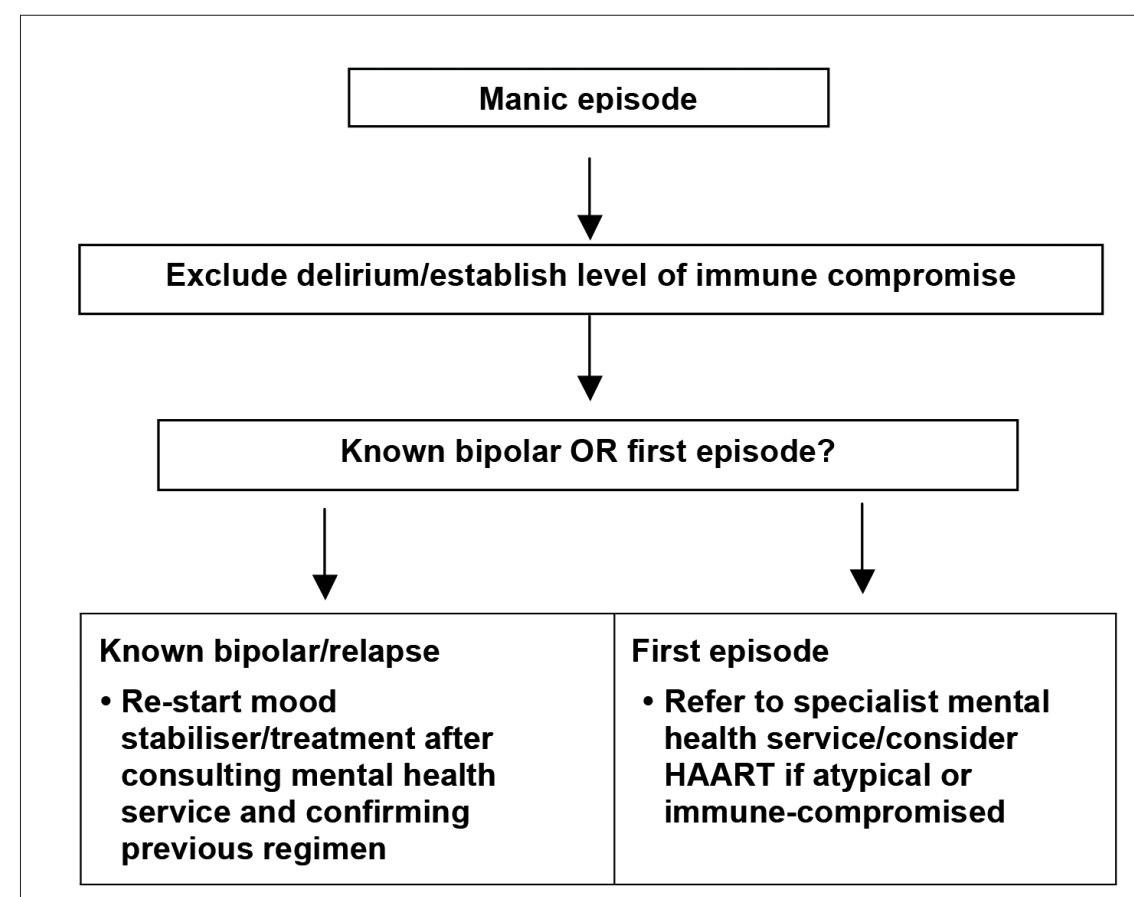

Fig. 2. An approach to the HIV-infected patient with mania. HAART = highly active antiretroviral therapy. 
effects of mood-stabilisers, especially in the case of neurocognitive dysfunction. Agents such as valproate, lamotrigine and lithium may be used cautiously, but carbamazepine (Tegretol) should be avoided because of potential interactions with ARVs (RTV, NVP and EFV), and the risk of neutropenia. $2 ., 9$

Valproate (Epilim) is generally considered the first-line treatment, but there is an additive risk of fatty liver with didanosine (ddI), abacavir (ABC), lamivudine (3TC), stavudine (d4T) and zidovudine (AZT). It is important to monitor the patient's liver function and adjust the dose accordingly, and it is advisable to test pre-treatment hepatic transaminases (AST/ALT) and platelet levels. The potential for teratogenesis in women of child-bearing age remains a concern. Some drug interactions do occur with LPV/r and LPV. Valproate levels may be decreased with co-administratiokn of RTV. An increase in the dose of valproate may be requried. No significant interaction occurs with tenofovir (TDF), NVP or EFV.,

Lithium should be avoided in patients with dehydration and renal function impairment. The agent is not always well tolerated, and it may be advisable to limit its use to individuals with higher $\mathrm{CD} 4$ cell counts. ${ }^{2}$ Careful monitoring of lithium levels is needed, usually 5 days after any dose adjustment, then monthly and 3 - 6-monthly thereafter.

Lamotrigine (Lamictin) can also be considered and is mainly used for depression in bipolar disorder. In most State facilities its use needs to be initiated by a psychiatrist or neurologist and the dose needs to be increased gradually to avoid Stevens-Johnson syndrome. RTV decreases lamotrigine levels by about $50 \%$ due to induction of glucuronidation; therefore, an increased lamotrigine dosage may be required.

Additional treatments that can be used in manic episodes include antipsychotics (such as Risperidone and Quetiapine) and benzodiazepines.

\section{Conclusion}

Many patients with HIV/AIDS have cooccurring mental health conditions that affect ART adherence, quality of life, morbidity and mortality. Although close collaboration between physicians, psychiatrists and other members of the multidisciplinary healthcare team is the ideal, many clinicians work in settings where psychiatric support is not readily available. This article is intended to guide prescribing antipsychotics in these settings.

\section{Additional resources}

- Medicines Information Centre: http://www. mic.uct.ac.za; tel: +27 (0)21 4066829

- HIV drug interactions: http://www.hivdruginteractions.org

- Psychiatry services and resources in the Western Cape province: http://www. hivmentalhealth.co.za.

\section{References}

1. Querques J, Freudenreich O. HIV and AIDS. In: Stern TA, Rosenbaum JF, Fava M, et al., eds. Massachusetts General Hospital Comprehensive
Clinical Psychiatry. Missouri, USA: Mosby, Elsevier, 2008.

2. Taylor D, Paton C, Kapur S. The Maudsley Prescribing Guidelines. 10th Edition. Place: Informa Healthcare 2009.

3. Smurzynski M, Wu K, Letendre S, et al. Effects of central nervous system antiretroviral penetration on cognitive functioning in the ALLRT cohort. AIDS 2011,25:357-365. [http://dx.doi.org/10.1097/ QAD.0b013e32834171f8]

4. Nath A, Sacktor N. Influence of HAART on persistence of HIV in the central nervous system. Curr Opin Neurol 2006;19:358-361.

5. Freeman M, Nkomo N, Kafaar Z, Kelly K. Menta disorder in people living with HIV/Aids in South Africa. South African Journal of Psychology 2007;38(3):489-500.

6. Kagee A, Martin L. Symptoms of depression and anxiety among a sample of South African patients living with HIV. AIDS Care 2010;22(2):159-165. [http://dx.doi.org/10.1080.09540120903111445]

7. Mills E, Montori V, Perri D, Phillips E, Koren G. Natural health product-HIV drug interactions: A systematic review. Int J STD AIDS 2005;16(3):181-186.

8. Swart AM, Jones J. EDL-Antiretrovirals Interactions Table. Cape Town: Medicines Information Centre, University of Cape Town, 2009. http://www.mic.uct ac.za/?page_id=47 (accessed 30 June 2012).

9. University of Liverpool. HIV Drug Interactions. http:// www.hiv-druginteractions.org (accessed 30 June 2012).

10. Nash JR, Nutt DJ. Pharmacotherapy of anxiety. Handbook Exp Pharmacol 2005;169:469-501.

11. Davidson J. Use of benzodiazepines in social anxiety disorder, generalized anxiety disorder, and post traumatic stress disorder. J Clin Psychiatry 2004;65:29-33

12. Work Group on HIV/AIDS, American Psychiatric Association. Practice guideline for the treatment of patients with HIV/AIDS. Am J Psychiatry 2006;163:1349-1354

13. Jover F, Cuadrado J, Andreu L, Merino J. Reversible coma caused by risperidone-ritonavir interaction. Clin Neuropharmacol 2002:25:251-253.

14. Singh D, Goodkin K. Choice of antipsychotic in HIV infected patients. J Clin Psychiatry 2007;68(3):479480.

15. Singh D, Goodkin K. Psychopharmacological treatment response of HIV infected patients to antipsychotic medication. J Clin Psychiatry 2007;68(4):631-632. 